\title{
Mining method selection by integrated AHP and PROMETHEE method
}

\author{
DEJAN BOGDANOVIC, DJORDJE NIKOLIC and IVANA ILIC \\ Technical Faculty in Bor, Belgrade University, Ul. Vojske Jugoslavije 12, 19210 Bor, Serbia \\ Manuscript received on May 4, 2010; accepted for publication on July 14, 2011
}

\begin{abstract}
Selecting the best mining method among many alternatives is a multicriteria decision making problem. The aim of this paper is to demonstrate the implementation of an integrated approach that employs AHP and PROMETHEE together for selecting the most suitable mining method for the "Coka Marin" underground mine in Serbia. The related problem includes five possible mining methods and eleven criteria to evaluate them. Criteria are accurately chosen in order to cover the most important parameters that impact on the mining method selection, such as geological and geotechnical properties, economic parameters and geographical factors. The AHP is used to analyze the structure of the mining method selection problem and to determine weights of the criteria, and PROMETHEE method is used to obtain the final ranking and to make a sensitivity analysis by changing the weights. The results have shown that the proposed integrated method can be successfully used in solving mining engineering problems.
\end{abstract}

Key words: AHP, mining, multicriteria decision making, PROMETHEE.

\section{INTRODUCTION}

Hamrin (1986) defines underground mining as a technique of recovering minerals from deposits below the earth's surface.

Important indicators of underground mining, such as net efficiency production, excavation cost, ore losses, ore dilution and the final financial effects depend on selected and applied mining method. Certainly the most important goal of the applied mining method is the achievement of a lower excavation cost and consequently a greater financial profit. However, the mining method selection cannot be solely based on these criteria.

Safe working conditions, ore excavation efficiency and ore dilution are also important characteristics of a selected mining method, which

Correspondence to: Dejan Bogdanovic

E-mail: dbogdanovic@tf.bor.ac.rs significantly affect the financial effects of the applied mining method.

Numerous considerations indicate that the undergorund mining method selection depends on the large number of relevant factors. These factors can be classified into three main groups, i.e.:

- mining-geological factors, such as: ground conditions, hangingwall and footwall, ore thickness, general shape, dip, plunge, depth below the surface, grade distribution, quality of resource, etc.

- mining-technical factors, such as: annual productivity, applied equipment, environmental considerations, mine recovery, flexibility of methods, machinery and mining rate, and

- economic factors, such as: capital cost, operating cost, mineable ore tons, orebody grades and mineral value. 
In practice, there are cases in which the mininggeological factors allow the application of a certain mining method, but its application is not justified from the aspect of financial effects. There are also cases in which a certain mining method considers the application of certain types of machinery, but it is not justified from the aspect of mining-technical factors.

Anyway, mining method selection is a timeconsuming and difficult process, requiring great advanced knowledge and experience. The process can be a hard task for mining engineers and managers. For a proper and effective evaluation, the decision maker may need to analyze a large amount of data and to consider many factors. There are several methodologies that were developed in the past for mining method selection. Bajkonurov (1969), Budko (1971), Imenitov (1970) and Popov (1970) have suggested a procedure for mining method selection that comprises two phases (preliminary mining method selection and the selection of the most suitable mining method from a group of applicable methods). The selection of the most suitable method from a group of applicable methods is made by the techno-economic model procedure. This model is based on the estimation of expected financial effects, which can be aquired by the implementation of each method from a group of applicable methods. The mining method with the best financial effects is selected.

Later, Boshkov and Wright (1973), Morrison (1976), Laubscher (1981) and Hartman (1987) have suggested a series of approaches for mining method selection. However, these approaches were inadequate for the development of a methodology that would automatically choose a mining method.

The first numerical approach for mining method selection was suggested by Nicholas (1981, 1992). This methodology rates different mining methods based on the rankings of specific input parameters. The mining method with the highest sum result is selected. Nicholas has suggested some modifications that involve the weighting of various categories, such as that of ore geometry, ore zone, hangingwall and footwall.

Miller et al. (1995) have developed the UBC methodology. The UBC mining method selection is a modification of the Nicolas methodology that better represents typical Canadian mining design practices. The main weaknesses of these approaches are in the fact that the importance of each selection criteria has not been considered.

An up-to-date approach considers mining method selection as a multi-criteria decisionmaking (MCDM) problem with a finite number of alternatives that have to be ranked considering many different and conflicting criteria. The advantage of these methods is that they can account for both financial and non-financial impacts. Among these methods, the most popular ones are scoring models, analytic hierarchy process - AHP, analytic network process - ANP, axiomatic design - AD, utility models, TOPSIS, ELECTRE and PROMETHEE. It is essential to develop all the elements related to the situation of MCDM in detail before selecting an appropriate MCDM method to solve the problem under consideration (Bufardi et al. 2004, Mergias et al. 2007).

Multi-criteria decision making (MCDM) methods, such as AHP and Fuzzy AHP, which are used for mining method selection problems in the literature, make the evaluations using the same evaluation scale and preference functions on the criteria basis. According to this, Ataei et al. (2008) have used the AHP approach for mining method selection. Otherwise, Bitarafan and Ataei (2004) have used different fuzzy methods as an innovative tool for criteria aggregation in mining decision problems. Also, Alpay and Yavuz (2009) have suggested a combination of AHP and fuzzy logic methods for underground mining method selection. The PROMETHEE method has some strength in the comparison with existing methods thanks to its simplicity and capacity to 
approximate the way that human mind expresses and synthesizes preferences when facing multiple contradictory decision perspectives. Decision Lab is a software that supports this method, and it also makes a sensitivity analysis for the results. This method provides a visual and powerful tool called Geometrical Analytic for Interactive Aid (GAIA) plane to identify conflicts among criteria and to group the alternatives (Albadvi et al. 2007).

In this paper, an AHP-PROMETHEE integrated approach for the selection of the most suitable mining method will be introduced, and the implementation process will be explained with a real world example. We shall use the AHP method to analyze the structure of the mining method selection problem and determine the weights of criteria. After that, we shall use the PROMETHEE method for final ranking. In this process the criteria, which have the greatest effect on the mining method selection, are determined by a sensitivity analysis.

This paper is divided into five sections. In Section "Introduction", the studied problem is discussed. Section "AHP and PROMETHEE methods" briefly describes the two proposed approaches. In Section "AHPPROMETHEE integrated methodology”, a proposed AHP-PROMETHEE integrated approach for mining method selection is presented in detail. How the proposed approach is used on a real example is explained in Section "A numerical example of proposed methodology". In last Section "Conclusion", the concluding remarks are is discussed.

\section{AHP AND PROMETHEE METHODS}

\section{AHP METHOD}

The Analytic Hierarchy Process (AHP) is a method developed by Saaty (1980) to support multicriteria decision making. This method is used in the decisionmaking process to help people setting priorities among the alternatives and making better decisions by taking into account qualitative and quantitative aspects of the decision.
Lee et al. (2001) defines the AHP as a quantitative technique that facilitates the structuring of a complex multi-attribute problem and provides an objective methodology that is applied to a wide variety of decisions in the human judgment process.

The AHP involves decomposing a complex MCDM problem into a multi-level hierarchical structure of objectives, criteria and alternatives. The decomposition into a hierarchy is based on previous studies, research and empirical experiences. Once the hierarchy has been developed, one moves to assess the relative importance of decision criteria, then compare the decision alternatives with respect to each criterion, and finally determine the overall priority for each decision alternative and the overall ranking of the decision alternatives.

The assessment of the relative importance of decision criteria and the comparison of decision alternatives with respect to each criterion is done by a pair-wise comparison, which involves the following three tasks:

- developing a comparison matrix at each level of the hierarchy, starting from the second level and going down;

- computing the relative weights for each element of the hierarchy; and

estimating the consistency ratio to check the consistency of the judgment.

Let $\left\{A_{1}, A_{2}, \ldots, A_{n}\right\}$ be $\mathrm{n}$ alternatives, and $\left\{w_{1}, w_{2}, \ldots, w_{n}\right\}$ be their current weights. The pairwise comparison is conducted by asking a decisionmaker or an expert questions, such as which criterion is more important with regard to the decision goal and by what scale (1-9), as shown in Table I.

TABLE I

Pair-wise Comparison Scale for AHP preference.

\begin{tabular}{ll}
\hline Verbal judgement & Numerical rating \\
\hline Equally preferred & 1 \\
Moderately preferred & 3 \\
Strongly preferred & 5 \\
Very strongly preferred & 7 \\
Extremely preferred & 9 \\
\hline \multicolumn{2}{c}{$2,4,6$ and 8 are intermediate values } \\
\hline
\end{tabular}


The answers to these questions are forming a pairwise comparison matrix that can be defined as follows:

$$
W=\left[w_{1} / w_{j}\right]=\left[\begin{array}{cccc}
w_{1} / w_{1} & w_{1} / w_{2} & \ldots & w_{i} / w_{n} \\
w_{2} / w_{1} & w_{2} / w_{2} & \ldots & w_{2} / w_{n} \\
\ldots & \ldots & \ldots & \ldots \\
w_{n} / w_{1} & w_{n} / w_{2} & \ldots & w_{n} / w_{n}
\end{array}\right]
$$

The matrix of the pairwise comparision $A=$ $\left[a_{i j}\right]$ represents the value of the expert's preference among individual pairs of alternatives $\left(A_{i}\right.$ versus $A_{j}$ for all $i, j=1,2, \ldots, n)$.

After this, the decision-maker compares pairs of alternatives for all the possible pairs, and the comparison matrix $A$ is obtained, where the element $a_{i j}$ shows the preference weight of $A_{i}$ obtained by comparison with $A_{j}$.

$$
A=\left[a_{i j}\right]=\left[\begin{array}{cccc}
1 & a_{12} & \ldots & a_{1 n} \\
1 / a_{1} & 1 & \ldots & a_{2 n} \\
\ldots & \ldots & \ldots & \ldots \\
1 / a_{1 n} & 1 / a_{2 n} & \ldots & 1
\end{array}\right]
$$

The $a_{i j}$ elements estimate the ratios $w_{i} / w_{j}$, where $w$ is the vector of current weights of the alternative (which is our goal).

The matrix has reciprocal properties, which are $a_{j i}=1 / a_{i j}$.

After all pair-wise comparison matrices are formed, the vector of weights $w=\left[w_{1}, w_{2}, \ldots, w_{n}\right]$ is computed on the basis of Satty's eigenvector procedure in two steps. First, the pair-wise comparison matrix, $A=\left[a_{i j}\right]_{n x n}$, is normalized, and then the weights are computed.

Normalization

$$
a_{i j}^{*}=a_{i j} / \sum_{i=1}^{n} a_{i j}
$$

for all $j=1,2, \ldots, n$.
Weight calculation

$$
w_{i}=\sum_{i=1}^{n} a_{i j}^{*} / n
$$

for all $j=1,2, \ldots, n$.

For a valid comparison, we need to check the consistency of the pair-wise matrix (CI ).

$$
C I=\left(\lambda_{\max }-n\right) /(n-1)
$$

where $\lambda_{\max }$ is an important validating parameter in AHP and is used as a reference index to screen information by calculating the Consistency Ratio $(C R)$ of the estimated vector. $C R$ can be calculated using the following equation:

$$
C R=C I / R I
$$

where $R I$ is the random consistency index obtained from a randomly generated pair-wise comparison matrix.

If $C R<0.1$, then the comparisons are acceptable. If $C R \geq 0.1$, the values of the ratio are indicative of inconsistent judgments. In this case, the original values in the pair-wise comparison matrix $A$ should be reconsidered and revised.

Determining the overall priority for each decision alternative and the overall ranking of decision alternatives is done by synthesizing the results over all levels. The weighted priorities of the decision alternatives are added components in order to obtain an overall weight (wAi ) or priority of each alternative over the entire hierarchy.

\section{PROMETHEE METHOD}

PROMETHEE (Preference Ranking Organization Method for Enrichment Evaluation) is an outranking method for a finite set of alternatives (Brans et al. 1984). These options include the choice of an appropriate preference function and the weighting given to each variable. The preference function defines how one object is to be ranked relative to another, and translates the deviation between the 
evaluations of two samples on a single parameter into a preference degree. The preference degree represents an increasing function of the deviation; hence, smaller deviations will contribute to weaker degrees of preference and larger ones to stronger degrees of preference. Six preference functions represented by specific shapes are available in the PROMETHEE method. Each shape is dependent on two thresholds, $Q$ and $P$. $Q$ is an indifference threshold representing the largest deviation that is considered negligible, and the preference threshold $P$ represents the smallest deviation that is considered as decisive. $P$ cannot be smaller than $Q$. The Gaussian threshold $\mathrm{S}$ is a middle value that is only used with the Gaussian preference function (Brans 1982, Brans and Vincke 1985).

The PROMETHEE method is based on the calculation of positive flow $\left(\Phi^{+}\right)$and negative flow $\left(\Phi^{-}\right)$for each alternative according to the given weight for each criterion. The positive outranking flow expresses how much each alternative is outranking all the others. The higher the positive flow $\left(\Phi^{+} \rightarrow 1\right)$, the better the alternative. The negative outranking flow expresses how much each alternative is outranked by all the others. The smaller the negative flow $\left(\Phi^{-} \rightarrow 0\right)$, the better the alternative. The PROMETHEE II complete ranking is based on a calculation of net outranking flow value $(\Phi)$ that represents the balance between the positive and negative outranking flows. The higher the net flow, the better the alternative (Brans and Mareschal 1994, Anand and Kodali 2008). The stepwise procedure for achieving this outranking method is presented below:

Step 1. Establishment of an impact matrix/double entry table. An impact matrix for the selected criteria $(j=1 \ldots n)$ and alternatives $(i=1 \ldots m)$ can be established by using cardinal (quantitative) and ordinal (qualitative) data.

Step 2. Application of the preference function $P(a, b)$. For each criterion, the selected preference function $P(a, b)$ is applied to decide how much the outcome a is preferred to $b$.

Step 3. Calculation of an overall or global preference index $\operatorname{Pi}(a, b)$ that represents the intensity of preference of $a$ over $b$.

$$
\pi(a, b)=\sum_{j=1}^{n} w_{j} \cdot P_{j}(a, b) ;\left(\sum_{j=1}^{n} w_{j}=1\right)
$$

Step 4. Calculation of outranking flows for each alternative $a \in A$ :

- Positive preference flow (outranking):

$$
\Phi^{+}(a)=\frac{1}{m-1} \sum_{x \in A} л(a, x)
$$

Negative preference flow (being outranked):

$$
\Phi^{-}(a)=\frac{1}{m-1} \sum_{x \in A} \pi(x, a)
$$

PROMETHEE I provides a partial ranking of the alternatives and more realistic information about incomparability, while PROMETHEE II provides a complete ranking of the alternatives by calculating the net flow:

$$
\Phi^{+}(a)=8+(\mathrm{a})-\Phi^{-}(a)
$$

Part of information about mutually incomparable alternatives is lost in the case of PROMETHEE II.

Step 5. Comparison of outranking flows (PROMETHEE I):

$\left\{\begin{array}{l}a P^{I} b \text { if }\left\{\begin{array}{l}\Phi^{+}(a)>\Phi^{+}(b) \text { and } \Phi^{-}(a)<\Phi^{-}(b) \\ \Phi^{+}(a)>\Phi^{+}(b) \text { and } \Phi^{-}(a)=\Phi^{-}(b) \\ \Phi^{+}(a)>\Phi^{+}(b) \text { and } \Phi^{-}(a)<\Phi^{-}(b)\end{array}\right. \\ a I^{I} b \text { if } \Phi^{+}(a)>\Phi^{+}(b) \text { and } \Phi^{-}(a)=\Phi^{-}(b) \\ a R b \text { otherwise }\end{array}\right.$ 
$(P, I, R$ represent preference, indifference and incomparability- respectively).

Both partial ranking (PROMETHEE I) and complete ranking (PROMETHEE II) of the set of considered alternatives can be proposed to the stakeholders in order to solve the decisionmaking problem.

Finally, the relative position of the alternatives in terms of contributions to the various criteria are given by the geometrical analysis for interactive aid (GAIA).

\section{AHP-PROMETHEE INTEGRATED METHODOLOGY}

Both PROMETHEE and AHP methods have strengths and weaknesses, and can be singly used for mining method selection. In this paper, our idea is to lessen the weakness and enhance the strengths of these two methods by the process of integration and combination of their proceedings.

Macharis et al. (2004) have analyzed the strengths and weaknesses of both PROMETHEE and AHP methods. They have made the comparative analysis of the following elements in both methods: the underlying value judgments, the structuring of the problem, the treatment of inconsistencies, the determination of weights, the evaluation elicitation, the management of the rank reversal problem, the support of group decisions, the availability of software packages and the possibility to visualize the problem. Based on this comparative analysis, we have concluded that a number of favorable characteristics of the AHP method could enhance PROMETHEE, namely at the level of structuring the decision problem and determining weights. The criteria weights, obtained by AHP, have a higher level of coherence, correlation, consistency and accuracy than weights determined on the basis of intuition or a domain specialist's knowledge, which is mostly used in the PROMETHEE method.

In this paper, the proposed integrated AHPPROMETHEE method for the mining method selection problem is consisted of four basic stages:
(1) Data gathering, (2) AHP computations, (3) PROMETHEE computations, (4) Decision making.

In the Data gathering stage, alternative mining methods and the criteria that will be used in their evaluation are determined, and the decision hierarchy is formed.

In the second stage, AHP computations are used for forming pairwise comparison matrices in order to determine the criteria weights. The individual evaluations are made by using the scale provided in Table I to determine the values of the elements of pairwise comparison matrices. Criterium Decision Plus software is used for computations in this process.

In the third stage-PROMETHEE computations, mining method priorities are found. Firstly, preference functions and parameters are determined by the authors. After this, the partial ranking with PROMETHEE I and the complete ranking with PROMETHEE II and GAIA plane are determined. Decision Lab software is used in this process.

In the last stage - Decision making, the best mining method is selected according to the rankings and GAIA plane obtained by PROMETHEE I and II.

The schematic representation of the proposed approach is presented in Figure 1.

The total ore reserves of "Coka Marin" are calculated as 1160000 tons, with an average grade of 1.0 'per cent' $\mathrm{Cu}, 2.6$ 'per cent' $\mathrm{Pb}, 6.4$ 'per cent' $\mathrm{Zn}, 2.71$ gram per ton $\mathrm{Au}$ and 24.22 gram per ton Ag. Table II. shows physical and mechanical characteristics of "Coka Marin" deposit.

\section{DATA GATHERING}

On the basis of the physical and mechanical characteristics of this deposit (Table II), mining-technical and economic factors, the following mining methods are considered: room and pillar $\left(A_{1}\right)$, room and pillar with fill $\left(A_{2}\right)$, shrinkage stoping $\left(A_{3}\right)$, cut and fill $\left(A_{4}\right)$ and sublevel caving $\left(A_{5}\right)$.

In Table III the criteria that have impact on the mining method selection are given. These 
Data gathering

- determining alternative mining methods determining the criteria

structuring decision hierarchy

AHP computations

- $\quad$ assigning criteria weights via AHP

PROMETHEE computations

determining the preference functions and parameters for the criteria

- partial ranking via PROMETHEE I

- complete ranking via PROMETHEE II

determining GAIA plane

Decision making

- selecting the best mining method

Fig. 1 - Schematic representation of the proposed method.

criteria comprise most of all relevant factors for the undergorund mining method selection.

There are three levels in the decision hierarchy. The overall goal of the decision process - the selection of the best mining method - is on the first level of the hierarchy. The criteria are on the second level, and alternatives are on the third level of the hierarchy.

\section{AHP COMPUTATIONS}

On the basis of the decision hierarchy for mining method selection problem, the criteria to be used in the evaluation process are assigned weights by using AHP method.
Let $\mathrm{A}=\left\{A_{1}, A_{2}, A_{3}, A_{4}, A_{5}\right\}$ be the set of possible mining alternatives, and $C=\left\{C_{1}, C_{2}, \ldots, C_{11}\right\}$ the set of selection criteria. A decision-maker is asked to form individual pairwise comparison matrix by using the scale given in Table I. Table IV shows the $11 \times 11$ pair-wise comparison matrix constructed to express the decision-makers' empirical estimate of the level of importance for each individual criterion. The maximum eigenvector was obtained from this matrix using the Criterium Decision Plus software.

Table V presents the results obtained from the computations based on the pairwise comparison matrix.

The excavation costs $\left(C_{9}\right)$, thickness $\left(C_{1}\right)$, ore excavation efficiency $\left(C_{7}\right)$ and work safety $\left(C_{10}\right)$ are determined as the most important criteria in the mining method selection process by AHP. The Consistency Ratio of the pairwise comparison matrix is calculated as $0.071<0.1$. So, the weights are shown to be consistent, and they can be used in the decision making process.

\section{PrometheE COMPUTATIONS}

On the basis of the evaluation criteria, mining method alternatives are evaluated and the evaluation matrix is formed. In this process, some criteria have a quantitative structure, while others have a qualitative structure or an uncertain structure that cannot be accurately measured. Accordingly, some criteria $\left(C_{6}, C_{7}\right.$ and $\left.C_{8}\right)$ are expressed on quantitative scales, while others are qualitative. The usage of both quantitative and qualitative scales ensures that all criteria are properly processed on the best way. The qualitative evaluation has been done by an expert on a 5-point scale - Table VI. The worst category is very poor (numerical value 1), and the best category is very high (numerical value 5).

The evaluations of these five alternatives, according to the previously stated criteria, i.e., evaluation matrix, are displayed in Table VII.

After the evaluation matrix is determined, mining method alternatives are evaluated by the 


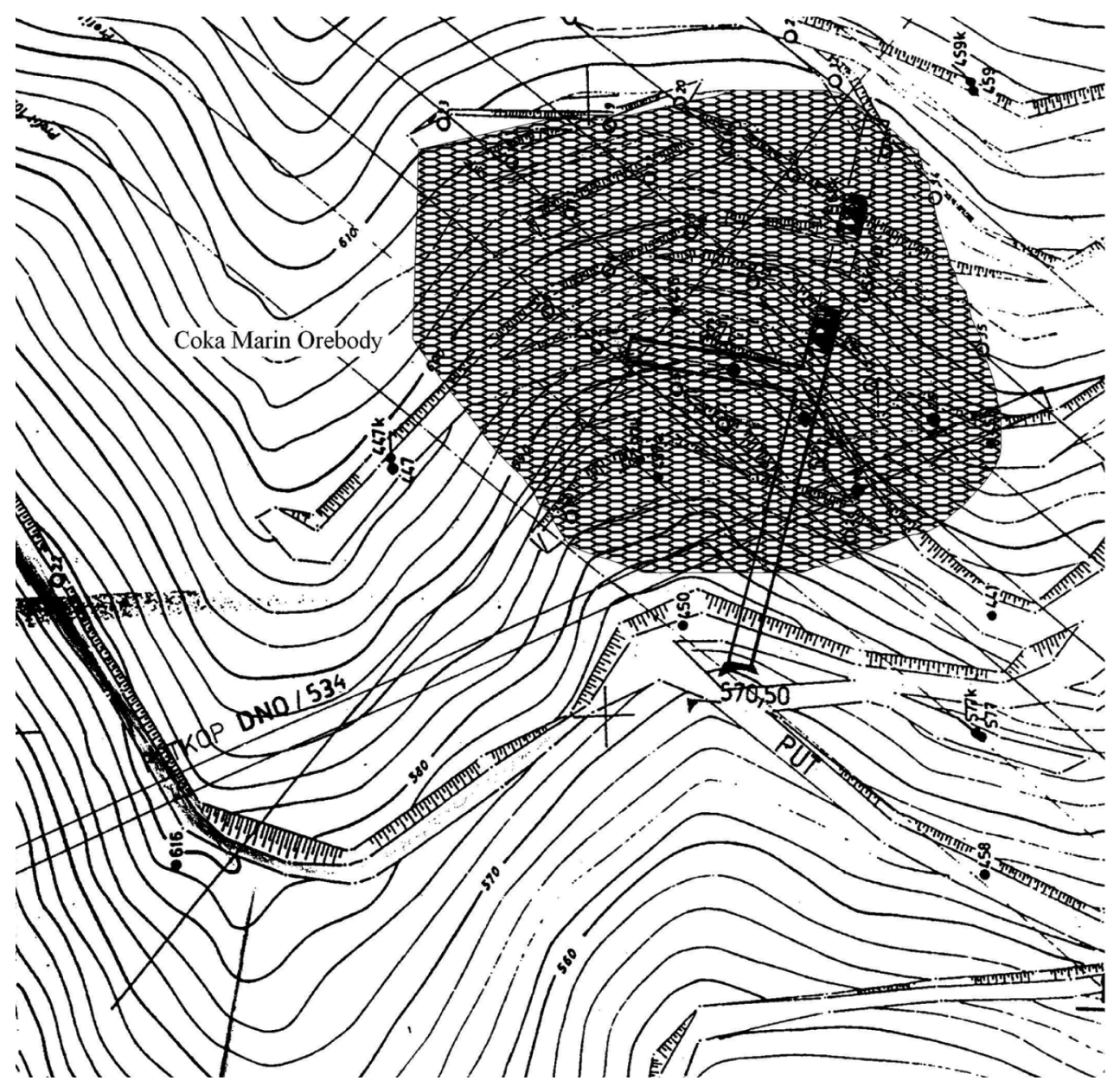

Fig. 2 - Schematic representation of the the "Coka Marin" mine.

TABLE II

Physical and mechanical characteristics of "Coka Marin" deposit.

\begin{tabular}{l|c|c|c|c}
\hline Parameter & Unit & Ore & Footwall & Haningwall \\
\hline Volumetric mass & $\mathrm{t} / \mathrm{m}^{3}$ & 4.07 & 2.68 & 2.55 \\
Porosity & $\%$ & 3.1 & 4.57 & 3.09 \\
Uniaxial compressive strength & $\mathrm{MPa}$ & 64.7 & 42.1 & 56.1 \\
Tensile strength & $\mathrm{MPa}$ & 9.1 & 5.2 & 7.3 \\
Inner frictional angle & degree & 34 & 35 & 35 \\
Module of elasticity & $\mathrm{GPa}$ & 37.4858 & 21.1705 & 25.5683 \\
Module of deformation & $\mathrm{GPa}$ & 36.207 & 19.9077 & 23.847 \\
Poisson coefficient & & 0.189 & 0.22 & 0.214 \\
Cohesion & $\mathrm{MPa}$ & 17.5 & 11.6 & 11.2 \\
Thickness & $\mathrm{m}$ & $40-50 \mathrm{~m}$ & - & - \\
Dip & degree & $65-75$ & - & - \\
Type & & Massive-sulphide & - & - \\
Depth & $\mathrm{m}$ & $20-270$ & - & - \\
\hline
\end{tabular}


TABLE III

Criteria for mining method selection.

\begin{tabular}{|c|c|c|}
\hline Criterion & Operation & Definition \\
\hline$\overline{C_{1}}$ & Thickness & $\begin{array}{l}\text { Power mining of ore body (distance between haningwall and footwall). } \\
\text { "Coka Marin" ore deposit has thickness from } 30 \mathrm{~m} \text { to } 50 \mathrm{~m} .\end{array}$ \\
\hline$C_{2}$ & Dip & $\begin{array}{l}\text { Inclination of ore deposit. The inclination of a geologic structure from } \\
\text { the horizontal; dip is always measured downwards at right angles to } \\
\text { the strike. Angle of inclination of "Coka Marin" ore deposit is from } \\
65^{\circ} \text { to } 75^{\circ} \text {. }\end{array}$ \\
\hline$C_{3}$ & $\begin{array}{l}\text { Rock substance } \\
\text { strength of ore }\end{array}$ & $\begin{array}{l}\text { Solidity of ore. It comprehends more characteristics of ore such as } \\
\text { compressive strength, tensile strength, cohesion, etc. }\end{array}$ \\
\hline$C_{4}$ & $\begin{array}{l}\text { Crack system } \\
\text { of ore }\end{array}$ & $\begin{array}{l}\text { The fracture pattern of rock. The term fracture or crack includes any } \\
\text { kind of discontinuity in a body of rock. Fractures include faults, shears, } \\
\text { joints and planes of fracture cleavage. "Coka Marin" ore deposit has } \\
\text { a moderated crack system. }\end{array}$ \\
\hline$C_{5}$ & Shape & $\begin{array}{l}\text { Contour or form of the ore deposit. "Coka Marin" ore deposit has a } \\
\text { lense shape. }\end{array}$ \\
\hline$C_{6}$ & $\begin{array}{l}\text { Coefficient of } \\
\text { development }\end{array}$ & $\begin{array}{l}\text { Development is defined as the work undertaken to open up ore reserves } \\
\text { as distinguished from the work of actual ore extraction. Coefficient of } \\
\text { development representst he total length in millimeters of excavations } \\
\text { undertaken to open up ore reserves in relation to total ore reserves in } \\
\text { tons }(\mathrm{mm} / \mathrm{t}) \text {. }\end{array}$ \\
\hline$C_{7}$ & $\begin{array}{l}\text { Ore excavation } \\
\text { efficiency }\end{array}$ & $\begin{array}{l}\text { Ore excavation efficiency can be defined as the degree of ore exploita- } \\
\text { tion (ratio between total excavated ore and geological ore reserve of } \\
\text { the ore deposit). }\end{array}$ \\
\hline$C_{8}$ & Ore dilution & The contamination of ore with barren wall rock in stopping. \\
\hline$C_{9}$ & Excavation costs & The sum of the costs of mining in relation to the total excavated ore. \\
\hline$C_{10}$ & Work safety & $\begin{array}{l}\text { Work safety depends on mining methods and its aim is to foster a safe } \\
\text { work environment. }\end{array}$ \\
\hline$C_{11}$ & $\begin{array}{l}\text { Terrain surface } \\
\text { preservation }\end{array}$ & $\begin{array}{l}\text { Terrain surface preservation depends on the applied mining method. } \\
\text { Among the considered mining methods, only sublevel caving causes } \\
\text { surface damage. }\end{array}$ \\
\hline
\end{tabular}

Decision Lab software. Table VIII shows the positive flow $\left(\phi^{+}\right)$, negative flow $\left(\phi^{-}\right)$and net flow $(\phi)$ values.

Firstly, the partial ranking is determined via PROMETHEE I (Fig. 3) on the basis of the flow values in Table VIII. PROMETHEE I uses positive and negative flow values to find the partial ranking.

Mining method $A_{2}$ is determined as the worst alternative according to the PROMETHEE I partial ranking. $A_{5}, A_{1}, A_{3}$ and $A_{4}$ alternatives are preferred to $A_{2}$ alternative. $A_{5}$ alternative is preferred to $A_{1}$ and $A_{4}$ alternatives. Also, $\mathrm{A}_{3}$ alternative is preferred to $A_{1}$ and $A_{4}$ alternatives. On the other hand, $A_{5}$ and $A_{3}$ (also $A_{1}$ and $A_{4}$ ) are incomparable alternatives. It is obvious that PROMETHEE I did not provide information about the best alternative.

The best alternative is identified by PROMETHEE II complete ranking (Fig. 4). Net flow values given in the last column of Table VIII are used in this process.

$A_{5}$ alternative (sublevel caving) is selected as the best alternative based on the information provided by PROMETHEE II, and the other 
TABLE IV

Pairwise comparison matrix for criteria and weights.

\begin{tabular}{c|c|c|c|c|c|c|c|c|c|c|c}
\hline Criteria & $C_{1}$ & $C_{2}$ & $C_{3}$ & $C_{4}$ & $C_{5}$ & $C_{6}$ & $C_{7}$ & $C_{8}$ & $C_{9}$ & $C_{10}$ & $C_{11}$ \\
\hline$C_{1}$ & 1 & 1 & 1 & 5 & 5 & 1 & 3 & 5 & 5 & 1 & 1 \\
$C_{2}$ & 1 & 1 & $1 / 3$ & 1 & 3 & $1 / 3$ & 1 & 1 & $1 / 5$ & $1 / 3$ & 1 \\
$C_{3}$ & 1 & 3 & 1 & 1 & 7 & 1 & 1 & 3 & $1 / 5$ & 1 & 3 \\
$C_{4}$ & $1 / 5$ & 1 & 1 & 1 & 3 & $1 / 3$ & $1 / 3$ & 1 & $1 / 5$ & $1 / 3$ & $1 / 3$ \\
$C_{5}$ & $1 / 5$ & $1 / 3$ & $1 / 7$ & $1 / 3$ & 1 & $1 / 9$ & $1 / 7$ & $1 / 3$ & $1 / 9$ & $1 / 7$ & $1 / 5$ \\
$C_{6}$ & 1 & 3 & 1 & 3 & 9 & 1 & 1 & 5 & $1 / 3$ & 1 & 1 \\
$C_{7}$ & $1 / 3$ & 1 & 1 & 3 & 7 & 1 & 1 & 3 & 1 & 1 & 3 \\
$C_{8}$ & $1 / 5$ & 1 & $1 / 3$ & 1 & 3 & $1 / 5$ & $1 / 3$ & 1 & $1 / 5$ & $1 / 3$ & $1 / 3$ \\
$C_{9}$ & $1 / 5$ & 5 & 5 & 5 & 9 & 3 & 1 & 5 & 1 & 1 & 1 \\
$C_{10}$ & 1 & 3 & 1 & 3 & 7 & 1 & 1 & 3 & 3 & 1 & 1 \\
$C_{11}$ & 1 & 1 & $1 / 3$ & 3 & 5 & 1 & $1 / 3$ & 3 & 3 & 1 & 1 \\
\hline
\end{tabular}

TABLE V

Results obtained from AHP computations.

\begin{tabular}{c|c|c}
\hline Criteria & Weights & CR \\
\hline$C_{1}$ & 0.115 & 0.071 \\
$C_{2}$ & 0.053 & \\
$C_{3}$ & 0.104 & \\
$C_{4}$ & 0.040 & \\
$C_{5}$ & 0.015 & \\
$C_{6}$ & 0.106 & \\
$C_{7}$ & 0.111 & \\
$C_{8}$ & 0.033 & \\
$C_{9}$ & 0.224 & \\
$C_{10}$ & 0.111 & \\
$C_{11}$ & 0.088 & \\
\hline
\end{tabular}

TABLE VI

Qualitative scale.

\begin{tabular}{c|c|c|c|c|c}
\hline $\begin{array}{c}\text { Qualitative } \\
\text { value }\end{array}$ & $\begin{array}{c}\text { Very } \\
\text { poor }\end{array}$ & Poor & Average & High & $\begin{array}{c}\text { Very } \\
\text { high }\end{array}$ \\
\hline $\begin{array}{c}\text { Numerical } \\
\text { value }\end{array}$ & 1 & 2 & 3 & 4 & 5 \\
\hline
\end{tabular}

alternatives are ranked in the order of $A_{3}$ (shrinkage stoping), $A_{1}$ (room and pillar), $A_{4}$ (cut and fill) and $A_{2}$ (room and pillar with fill).

The advantage of Decision Lab software package reflects in the use of GAIA (Geometrical Analysis for Interactive Assistance). Considering that 1 value is satisfactory $(1=87.92 \%)$, the validity of using this tool can be discussed, where, 1 presents the measure of the amount of information being preserved by the defined model. In the real world, the applications of the value of 1 has always been larger than $60 \%$, and in most cases larger than $80 \%$ (Brans and Mareschal 1994).

Based on the GAIA plane, it is possible to 
TABLE VII

Evaluation matrix.

\begin{tabular}{c|c|c|c|c|c|c|c|c|c|c|c}
\hline Criteria & $C_{1}$ & $C_{2}$ & $C_{3}$ & $C_{4}$ & $C_{5}$ & $C_{6}$ & $C_{7}$ & $C_{8}$ & $C_{9}$ & $C_{10}$ & $C_{11}$ \\
\hline Unit & - & - & - & - & - & $\operatorname{mm} / \mathrm{t}$ & $\%$ & $\%$ & - & - \\
\hline Max/min & $\max$ & $\max$ & $\max$ & $\max$ & $\max$ & $\min$ & $\max$ & $\min$ & $\max$ & $\max$ & $\max$ \\
\hline Weights & 0.115 & 0.053 & 0.104 & 0.040 & 0.015 & 0.106 & 0.111 & 0.033 & 0.224 & 0.111 & 0.088 \\
\hline $\begin{array}{c}\text { Preference } \\
\text { function }\end{array}$ & Level & Level & Level & Level & Level & Linear & Linear & Linear & Level & Level & Level \\
\hline$A_{1}$ & 3 & 2 & 2 & 2 & 3 & 2.155 & 55.0 & 5.0 & 3 & 3 \\
\hline$A_{2}$ & 3 & 2 & 2 & 2 & 3 & 2.155 & 55.0 & 8.0 & 2 & 4 & 5 \\
\hline$A_{3}$ & 5 & 5 & 4 & 3 & 4 & 1.988 & 60.0 & 10.0 & 3 & 4 & 2 \\
\hline$A_{4}$ & 2 & 4 & 2 & 2 & 3 & 2.223 & 90.0 & 10.0 & 2 & 3 & 5 \\
\hline$A_{5}$ & 4 & 4 & 4 & 4 & 4 & 2.544 & 85.0 & 15.0 & 4 & 4 & 1 \\
\hline
\end{tabular}

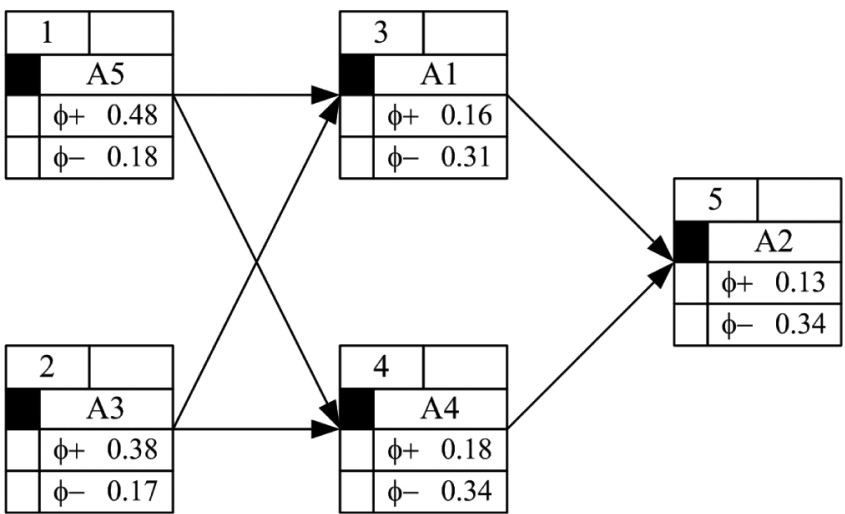

Fig. 3 - PROMETHEE I partial ranking.

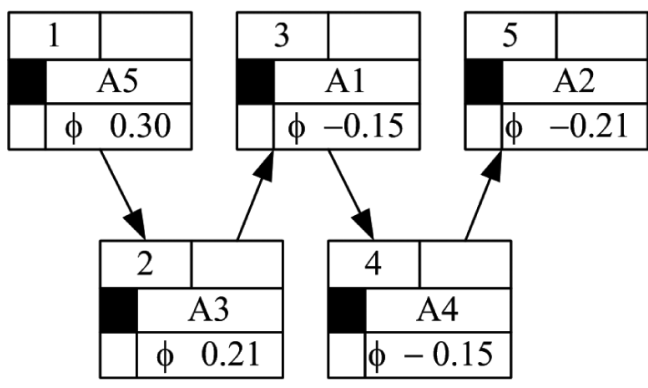

Fig. 4 - PROMETHEE II complete ranking.

TABLE VIII

PROMETHEE flows.

\begin{tabular}{c|c|c|c}
\hline Alternatives & $\phi^{+}$ & $\phi^{-}$ & $\phi$ \\
\hline$A_{1}$ & 0,1583 & 0,3082 & $-0,1499$ \\
$A_{2}$ & 0,1262 & 0,3368 & $-0,2106$ \\
$A_{3}$ & 0,3807 & 0,1677 & 0,2130 \\
$A_{4}$ & 0,1821 & 0,3364 & $-0,1543$ \\
$A_{5}$ & 0,4816 & 0,1797 & 0,3019 \\
\hline
\end{tabular}




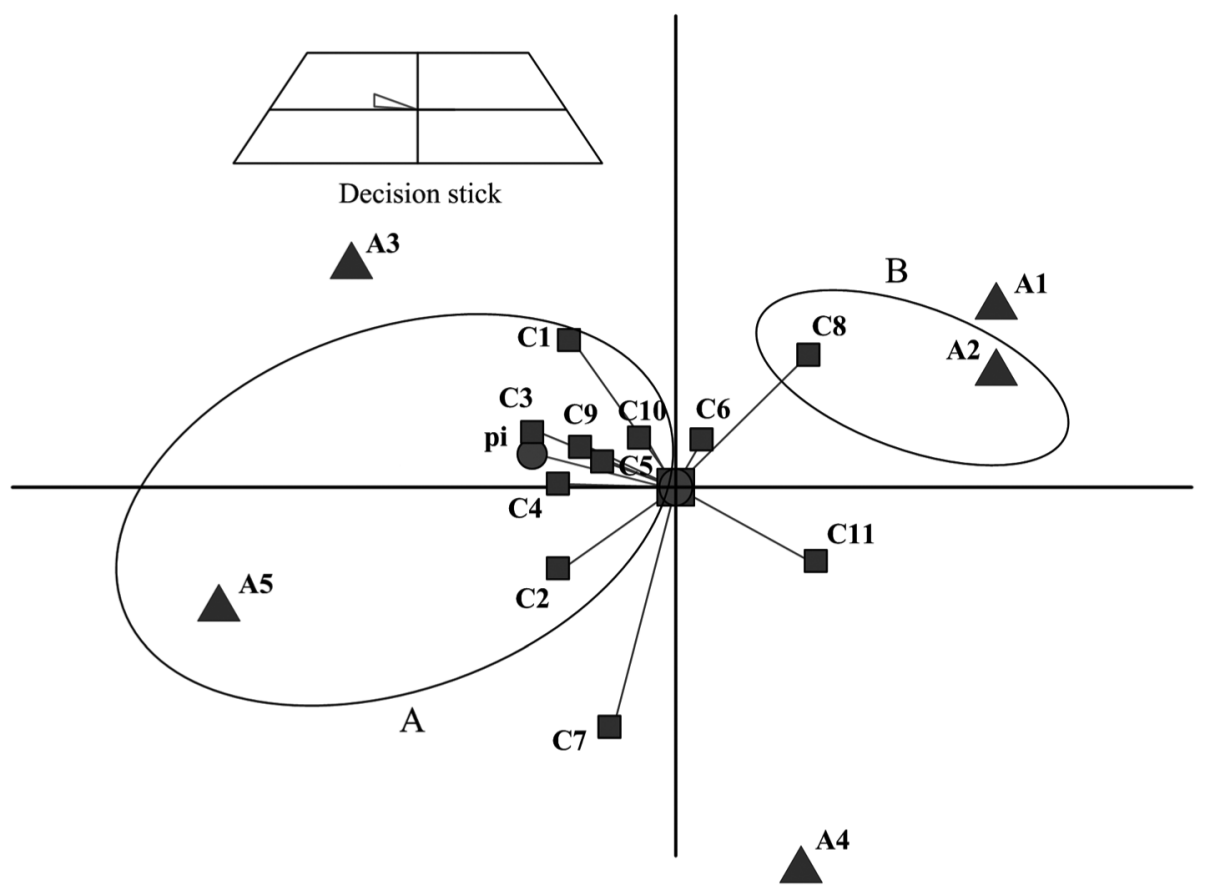

Fig. 5 - GAIA plane for mining method selection.

TABLE IX

Stability intervals.

\begin{tabular}{c|c|c|c}
\hline Criteria & Weight & Min & Max \\
\hline$C_{1}$ & 0.1150 & 0.1062 & 0.2277 \\
$C_{2}$ & 0.0530 & 0.0029 & 0.0569 \\
$C_{3}$ & 0.1040 & 0.0000 & Infinity \\
$C_{4}$ & 0.0400 & 0.0000 & Infinity \\
$C_{5}$ & 0.0150 & 0.0000 & Infinity \\
$C_{6}$ & 0.1060 & 0.0263 & 0.2278 \\
$C_{7}$ & 0.1110 & 0.0676 & 0.1144 \\
$C_{8}$ & 0.0330 & 0.0292 & 0.1376 \\
$C_{9}$ & 0.2240 & 0.2170 & Infinity \\
$C_{10}$ & 0.1110 & 0.0000 & 0.2012 \\
$C_{11}$ & 0.0880 & 0.0000 & 0.0997 \\
\hline
\end{tabular}

easily determine the discriminative strength of each criterion, as well as the aspects of consistency and inconsistency as the quality of each alternative by every criterion. The alternatives are shown by triangles, and the criteria are presented as axes with square endings.

The eccentricity of the position of square criteria is representing the strength of influence of that criterion, while the similarity in preference among certain criteria is defined with almost the same direction of axes of these criteria.

For the ranking, it is possible to determine the agreement among criteria $C_{1}, C_{2}, C_{3}, C_{4}, C_{5}, C_{6}, C_{9}$ and $C_{10}$, while the criteria $C_{7}, C_{8}$ and $C_{11}$ are not in compliance with other criteria. Also, the alternative position (triangles) determines the strength or weakness in relation to the alternative criteria. The closer orientation axis of the criteria to an alter- 
native shows the better position of the alternative according to that criteria. The alternative $A_{5}$ (Cluster A) in Figure 5 can be determined as the best option because it is the closest alternative regarding the axis directions of criteria with the greatest impact $\left(C_{1}, C_{3}\right.$, $C_{9}$ and $C_{10}$ ), and is directed to the nearest position of the decision stick $p i$, which defines the compromise solution in accordance with the weighted criteria. Contrary to it, the alternative $A_{2}$ is the worst one because it is good only by one weak criterion $C_{8}$ (Cluster B), and it is opposes to the direction of the decision stick $p i$ which results have also been obtained through the PROMETHEE ranking.

\section{DECISION-MAKING}

According to the integrated AHP and PROMETHEE computations, it is decided that the sublevel caving $\left(A_{5}\right)$ is the most suitable mining method for the "Coka Marin" underground mine. It was also analyzed how the variation in the criteria weights after the decision will affect the ranking. The sensitivity analysis has been performed, and the resulting "stability intervals" values are given in Table IX. Table IX gives for each criterion the limits within the weights' values, which can vary without changing the PROMETHEE II complete ranking. From the result of the sensitivity analysis, it is clear that Ore excavation efficiency $\left(C_{7}\right)$ have the greatest impacts on the complete ranking.

\section{CONCLUSION}

In this paper, a decision approach is provided for mining method selection problem. Mining method selection is the most important decision made in a mine project. The selection of a suitable mining method for an ore deposit requires the consideration of a numerous criteria, such as mining-geological factors, economic factors and miningtechnical factors. This selection problem is based on the comparisons of mining method alternatives according to the identified criteria.
An integrated AHP and PROMETHEE decision making method has been used in the proposed approach for excavating the "Coka Marin" polymetallic ore deposit. The proposed approach differs from the present mining method selection in the literature. Here, AHP is used to assign weights to the criteria for mining method selection, while PROMETHEE is used for the complete ranking of the alternatives. The weights obtained from AHP are used in PROMETHEE computations, and the alternative priorities are determined based on these weights. In this study it was shown that the calculation of the criteria weights is important in the PROMETHEE method, and they could change the ranking.

The proposed integrated method can help decisionmakers to easily choose and analyze factors and attributes. The strengths of this approach over the existing methods are as follows: the PROMETHEE method takes into account the preference function of each criterion, which is determined by the decision-makers; each criterion is evaluated on a different basis, and it is possible to make better decisions. PROMETHEE I provides a partial ranking to identify the alternatives that cannot be compared and the alternatives that are indifferent, while PROMETHEE II provides a complete ranking for alternatives. The GAIA plane is a powerfull tool that suggests a differentiation power to the criteria, similar criteria, independent criteria and opposite criteria. By utilizing the PROMETHEE method to make a sensitivity analysis of the results, the most effective criterion in decision making is determined. These opportunities are not available in current methods, such as AHP, fuzzy AHP, ELECTRE, TOPSIS, etc.

Therefore, on the basis of the obtained results by the proposed integrated AHP and PROMETHEE method, the most suitable mining method for extracting the "Coka Marin" polymetallic ore is the sublevel caving method (alternative $A_{5}$ ).

The proposed model has only been implemented on a mining method selection problem in the RTB 
Bor company, but the company management has found the proposed model satisfactory and implementable.

\section{ACKNOWLEDGMENTS}

Research funded by Serbian Ministry of Education and Technological Development as part of the project No.: TR-34023. The authors also feel indebted to the company Visual Decision Inc. Montreal, Canada, for providing the software package Decision Lab 2000 free of charge.

\section{RESUMO}

A seleção do melhor método de mineração dentre muitas alternativas, é um problema de tomada de decisão baseado em múltiplos critérios. O objetivo do presente artigo é demonstrar a implementação de um enfoque integrado que adota AHP e PROMETHEE conjuntamente para a seleção do método de mineração mais adequado para a mina subterrânea "Coka Marin" localizada na Sérvia. O problema leva em consideração cinco possíveis métodos de mineração e onze critérios para sua avaliação. Os critérios são precisamente escolhidos de forma a incorporar os parâmetros mais importantes que impactam a seleção de métodos de mineração, tais como, propriedades geotécnicas, parâmetros econômicos e fatores geográficos. AHP é usado para a análise da estrutura do problema de seleção do método de mineração e para determinar pesos associados aos critérios. O método PROMETHEE é usado para determinar a classificação final e para fazer uma análise de sensibilidade através da variação dos pesos. Os resultados demonstraram que o método integrado proposto pode ser usado com sucesso na solução de problemas de engenharia de minas.

Palavras-chave: AHP, mineração, processo de decisão baseado em múltiplos critérios, PROMETHEE.

\section{REFERENCES}

AlbadVI A, CHAHARSOOGHI SK AND ESFAHANIPOUR A. 2007. Decision making in stock trading: An application of PROMETHEE. Eur J Oper Res 177(2): 673-683.
ALPAY S AND YAVUZ M. 2009. Underground mining method selection by decision making tools. Tunn Undergr Space Tech 24: 173-184.

ANAND G AND KODALI R. 2008. Selection of lean manufacturing systems using the PROMETHEE. Journal of Modelling in Management 3(1): 40-70.

Ataei M, JAMshidi M, SEREShKi F AND JALALi SME. 2008. Mining method selection by AHP approach. J S Afr I Min Metall 108: 741-749.

BAJKONUROV AO. 1969. Classification and selection of underground mining development methods. Nauka. Alma-Alta.

BITARAFAN MR AND ATAEI M. 2004. Mining method selection by multiple criteria decision making tools. J S Afr I Min Metall, p. 493-498.

BoshKov SH AND Wright FD. 1973. Basic and Parametric Criteriain the Selection, Design and Development of Underground Mining Systems. SME Mining Engineering Handbook. CUMMINS AB AND GIVEN IA (Eds), vol. 1, SME-AIME, New York, p. 12.2-12.13.

BRANS JP. 1982. L'ingénièrie de la décision; Elaboration d'instruments d'aide à la décision. La méthode PROMETHEE, in NADEAU R ET LANDRY M (Eds), L'aide à la décision: Nature, Instruments et Perspectives d'Avenir. Presses de l'Université Laval, Québec, Canada, p. 183-213.

BRANS JP AND MARESCHAL B. 1994. The PROMCALC and GAIA decision support system for MCDA. Decis

Support Syst 12: 297-310.

Brans JP, Mareschal B AND VincKe PH. 1984. PROMETHEE: A new family of outranking methods in multicriteria analysis. Operational Research. North-Holland, Amsterdam, p. 477-490.

BRANS JP AND VINCKE PH. 1985. A preference ranking organisation method: The PROMETHEE method for MCDM. Manage Sci 31(6): 647-656.

BUDKO VA. 1971. Selection of advanced development systems. Nedra. Moskow.

Bufardi A, GHEORghe R, Kiritsis D AND Hirouchakis P. 2004. Multicriteria decision-aid approach for product endof-life alternative selection. In J Prod Res 42: 3139-3157.

HAMRIN H. 1986. Guide to underground mining methods and applications. Atlas Copco. Stockholm. HARTMAN HL. 1987. Introductory Mining Engineering. Wiley, New York, $633 \mathrm{p}$.

IMENITOV RV. 1970. Underground mining development processes. Nedra. Moskow.

LAUBSCHER DH. 1981. Selection of Mass Underground Mining Methods. Design and Operation of Caving and Sublevel Stoping Mines. Chap. 3, D. Stewart, ed., SMEAIME, New York, p. 23-38.

LEE WB, LAU H, LIU Z AND TAM S. 2001. A fuzzy analytical hierarchy process approach in modular product design. Expert Syst 18(1): 32-42. 
Macharis C, Springael J, DE BRUCKer K AND Verbeke A. 2004. PROMETHEE and AHP: The design of operational synergies in multicriteria analysis. Strengthening PROMETHEE with ideas of AHP. Eur J Oper Res 153(2): 307-317.

Mergias I, Moustakas K, Papadopoulos A and Loizidou M. 2007. Multi-criteria decision aid approach fort he selection of the best compromise management scheme for ELVs: The case of Cyprus. J Hazardous Mater 147: $706-717$.

Miller L, Pakalnis R and Poulin R. 1995. UBC Mining method Selection, Mine planning and equipment selection. (MPES), SINGHAL RK ET AL. (Eds), Balkama, Rotterdam.
Morrison RGK. 1976. A Philosophy of Ground Control. McGill University, Montreal. Canada, p. 125-159.

Nicholas DE. 1981. Method Selection - A Numerical Approach. Design and Operation of Caving and Sublevel Stoping Mines, Chap. 4, STEWART D (Ed), SME-AIME, New York, p. 39-53.

NICHOLAS DE. 1992. Selection method. SME Mining Engineering Handbook. HARTMAN HL (Ed), $2^{\text {nd }}$ ed., Society for Mining Engineering, Metallurgyand Exploration, Inc, p. $2090-2106$.

PoPOV NG. 1970. Technology and complex mechanization for underground mining. Nedra. Moskow.

SAATY TL. 1980. The Analytical Hierarchy Process. McGraw-Hill. New York. 